'Escuela de Medicina, Universidad de los Andes. Santiago, Chile. ${ }^{2}$ Unidad de Paciente Crítico. Hospital Militar de Santiago. Santiago, Chile. ${ }^{3}$ Visiting Scholar, Clinical and Translational Research Institute, University of California San Diego. San Diego, USA. ${ }^{4}$ Institute for Regenerative Medicine and Biotherapy. Montpellier, France. aphD.

Apoyado por Fondo de Ayuda a la Investigación (FAI) Universidad de los Andes.

Recibido el 31 de marzo de 2015 aceptado el 15 de septiembre de 2015.

Correspondencia a: Francisco Espinoza V. Escuela de Medicina, Universidad de los Andes. Avenida Álvaro del Portillo 12455. Las Condes. Santiago, Chile.

Teléfono: +56224129307 fespinoza@miuandes.cl

\section{Escenario actual y perspectivas de la terapia con células madre mesenquimales en medicina intensiva}

\author{
FRANCISCO ESPINOZA ${ }^{1,2,3}$, FELIPE ALIAGA ${ }^{2}$, \\ PATRICIA LUZ CRAWFORD ${ }^{4, a}$
}

\section{Overview and perspectives of mesenchymal stem cell therapy in intensive care medicine}

Development of innovative therapies in intensive care medicine is particularly important since diseases as sepsis, acute respiratory distress syndrome (ARDS) and acute renal injury (AKI) have an elevated morbidity and mortality in spite of current gold-standard approaches. Mesenchymal stem cells (MSC) may have a promising role due to their properties in immunomodulation, tissue reparation and microbial clearance. Preclinical data and results of a systematic review of PubMed, PMC and ClinicalTrials.gov have been included to review the role of MSC therapy in sepsis, ARDS and AKI. A description of MSC biology, sources and benefits in preclinical models was included. A phase I/II clinical trial (RCT) is recruiting neutropenic patients with septic shock. In ARDS, the START trial (Stem cells in ARDS Treatment) is a phase I/II study of bone marrow-derived human MSC (hMSC) that is currently recruiting patients. In AKI, a phase I study has demonstrated the safety of hMSCs infusion in patients undergoing cardiac surgery with high risk to develop AKI. A phase II study is still active. The results of these studies will determine the real feasibility of MSC therapy in critically ill patients.

(Rev Med Chile 2016; 144: 222-231)

Key words: Acute Kidney Injury; Mesenchymal stromal cells; Respiratory Distress Syndrome, Adult; Sepsis.

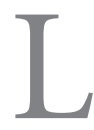

a Unidad de Cuidados Intensivos concentra gran parte de la mortalidad hospitalaria. El grupo más ominoso está integrado por aquellos pacientes que cursan con sepsis severa o shock séptico, síndrome de distrés respiratorio agudo (SDRA) e/o injuria renal aguda (IRA).

La mortalidad es considerablemente elevada, alcanzando $45 \%$ en el SDRA grave y $18,4 \%$ en la sepsis severa ${ }^{1,2}$. En el campo farmacológico no han existido avances sustanciales y los esfuerzos globales se han enfocado en la implementación de protocolos de diagnóstico precoz y de tratamientos basados en metas. Estas medidas han contribuido a una disminución de la mortalidad, pero no han cambiado sustancialmente el pronóstico.
En este contexto, un cambio en el enfrentamiento terapéutico parece fundamental. La terapia celular, específicamente el uso de células madre mesenquimales (MSC), surge como una opción dado su potencial inmunomodulador y regenerativo. Los datos preclínicos son positivos y han dado pie a la realización de los primeros ensayos clínicos en sepsis, SDRA e IRA.

El objetivo del artículo es ofrecer una visión al clínico de la realidad actual de la terapia celular en medicina intensiva. Para ello se ha realizado una descripción de las propiedades, funciones y fuentes de las MSC para, posteriormente, abordar la evidencia en modelos preclínicos y los estudios clínicos en tres patologías: sepsis, SDRA e IRA. 


\section{Métodos}

Se realizó una revisión sistemática de artículos científicos y reportes de ensayos clínicos en las bases de datos PubMed, PMC y ClinicalTrials.gov desde 1968 hasta marzo de 2015.

Los términos utilizados en la búsqueda electrónica fueron: "cell-based therapy", "mesenchymal stem cells", "mesenchymal stromal cells", "critical care medicine", "intensive care unit", "sepsis", "acute respiratory distress syndrome" y "acute kidney injury". Una revisión manual de cada publicación fue realizada con el objeto de detectar otros artículos de interés que fueron finalmente incluidos en esta revisión. Se incluyeron reportes publicados en inglés o español.

\section{Células madre mesenquimales (MSC)}

\section{Características generales}

Las MSC fueron aisladas por Friedestein et al. en 1968 a partir de la médula ósea (MO) de ratones y cobayos ${ }^{3}$. Inicialmente fueron descritas como células adherentes generadoras de unidades formadoras de colonias (CFU) fibroblastoides, constitutivas del estroma medular y cuya función era mantener el microambiente hematopoyético ${ }^{4}$. Estudios posteriores demostraron la capacidad proliferativa de las CFU, su habilidad para autorrenovarse y su potencial para originar adipocitos, condrocitos y osteoblastos. Esta capacidad de originar células pertenecientes a tejidos mesenquimales sugirió la existencia de una célula madre presente en la MO, lo cual se denominó años más tarde como MSC5.

Estas células son fácilmente aisladas y expandidas in vitro. Son multipotenciales, diferenciándose hacia adipocitos, osteoblastos, condrocitos, tenocitos, miocitos, estroma hematopoyético y fibroblastos ${ }^{6}$. Presentan plasticidad para diferenciarse ex-vivo a tejidos no mesodermales, como neuronas, astrocitos, oligodendrocitos, neumocitos y hepatocitos ${ }^{7,8}$.

La Sociedad Internacional de Terapia Celular (ISCT) ha sugerido criterios mínimos para definir una MSC: a) adherencia al plástico bajo condiciones estándar de cultivo; b) expresión de marcadores de superficie como CD105, CD90, CD73 y ausencia de marcadores, sobre todo hematopoyéticos, incluyendo CD45, CD34, CD14 y CD11b; c) capacidad de diferenciación in-vitro hacia los otros linajes de origen mesodermal (adipocitos, condrocitos, osteoblastos) ${ }^{9}$.

\section{Fuentes}

La MO es la fuente mejor caracterizada de MSC. Su recuperación requiere, por ende, de una punción de $\mathrm{MO}$. El volumen aspirado va entre 60 y $70 \mathrm{~mL}$ y las MSC corresponden entre 0,001 y $0,01 \%$ de las células nucleadas aisladas ${ }^{10}$, variando en función de la edad del donante. Alternativamente, ha sido posible aislar MSC del tejido adiposo, cordón umbilical y placenta, tejido dental (pulpa, ligamento periodontario, etc.) y tejido endometrial ${ }^{11-14}$.

\section{Propiedades que favorecen el uso terapéutico de MSC}

a) Una vez recuperadas, las células son cultivadas ex vivo adhiriéndose a la superficie plástica de una botella de cultivo. La expansión de la población celular es rápida y se realiza mediante la transferencia secuencial de las células a un número cada vez mayor de medios de cultivo, pudiendo alcanzar 20-30 veces la población original en un plazo inferior a dos semanas. Lo anterior, permite tener disponible en corto tiempo un stock que puede ser usado con fines terapéuticos. La expansión de la población de MSC no afecta la multipotencialidad y, en comparación de las células madre de origen embrionario (ESC), su potencial tumorigénico es muy bajo y su capacidad de diferenciarse es restringido ${ }^{15}$.

b) Tienen una baja inmunogenicidad. No expresan moléculas de MHC tipo II ni co-estimuladoras de linfocitos T (CD80, CD86) y poseen una expresión constitutiva mínima de MHC tipo I, lo que facilita su uso para trasplantes alogénicos ${ }^{16}$.

c) Tienen propiedades inmunomoduladoras. Por una parte, son capaces de suprimir las respuestas asociadas a procesos inflamatorios promovidas por células del sistema inmune adquirido (linfocitos T helper 1 (Th1), Th17, T-CD8 y linfocitos B). Por otra parte, inducen una respuesta de células del sistema inmune asociadas a procesos antiinflamatorios (células dendríticas [DC] tipo 2 [supresoras], macrófagos tipo 2, Th2 y T reguladores) ${ }^{17-19}$. 
d) Las MSC median procesos de reparación tisular. Son capaces de sintetizar componentes de la matriz extracelular como fibronectina, versicán y colágeno- 1 , y también factores solubles como G-CSF, GM-CSF, VEGF, FGF7, IL-6, IL-7, IL-11, TGF- $\beta 1$, SDF-1, entre otros ${ }^{20}$.

Los efectos mediados por las MSC ocurren sin la inclusión o injerto de éstas en un tejido (engraftment). Los estudios con detección por fluorescencia muestran que la vida media de las células luego de ser infundidas es reducido, con una población inferior a $1 \%$ una semana post-infusión $^{21,22}$. En este contexto, las MSC actuarían de manera directa entablando contacto con células del sistema inmune u otra $\mathrm{o}$, indirectamente, mediante la liberación de factores paracrinos, ejerciendo una acción de coordinación en procesos como reparación tisular, neovascularización, apoptosis, fagocitosis e inmunomodulación ${ }^{23}$.

\section{Uso de MSC en modelos preclínicos de sepsis, SDRA e IRA}

\section{Sepsis}

Han sido utilizados dos modelos de sepsis por peritonitis: 1) la inyección intraperitoneal de bacterias o componentes bacterianos, como el lipopolisacárido (LPS) y 2) el modelo de ligadura y punción cecal (CLP). La administración de MSC se realizó mediante una inyección intravenosa (IV) en la vena yugular o en la cola del ratón. Como placebo se utilizó una inyección de fibroblastos, suero salino o MSC inactivados por shock térmico. El tratamiento de soporte consistió en antibióticos $\mathrm{y}$ volumen, los que fueron administrados a los grupos experimental y placebo ${ }^{24-29}$.

El momento de la infusión y la dosis de MSCs fue variable entre los estudios. Desde $24 \mathrm{~h}$ previo a la inducción de la sepsis, hasta infusiones repetitivas hasta 48 h después. La dosis total se encuentra entre las 2,5 y 7,5 x $10^{5}$ MSC. Los detalles de la maniobra experimental y los efectos biológicos y clínicos inducidos por las MSC en sepsis se resumen en la Tabla 1.

El uso de MSC en sepsis conduce a una modulación de la respuesta inmune, atenuando el síndrome de respuesta inflamatoria sistémica (SIRS) y optimizando los mecanismos antimicrobianos (Figura 1). El resultado en modelos murinos es aumento de la sobrevida y disminución de la falla orgánica asociada a la sepsis.

Han sido descrito disminuciones del nivel plasmático de citoquinas pro-inflamatorias tales como IL-1 $\beta$, IL-6 y TNF- $\alpha^{24-29}$. La expresión de estas citoquinas disminuye también en el tejido cardiaco, pulmonar y renal. Por el contrario, se ha observado incremento en los niveles plasmáticos de IL-10. Nemeth et al. ${ }^{25}$ han descrito que

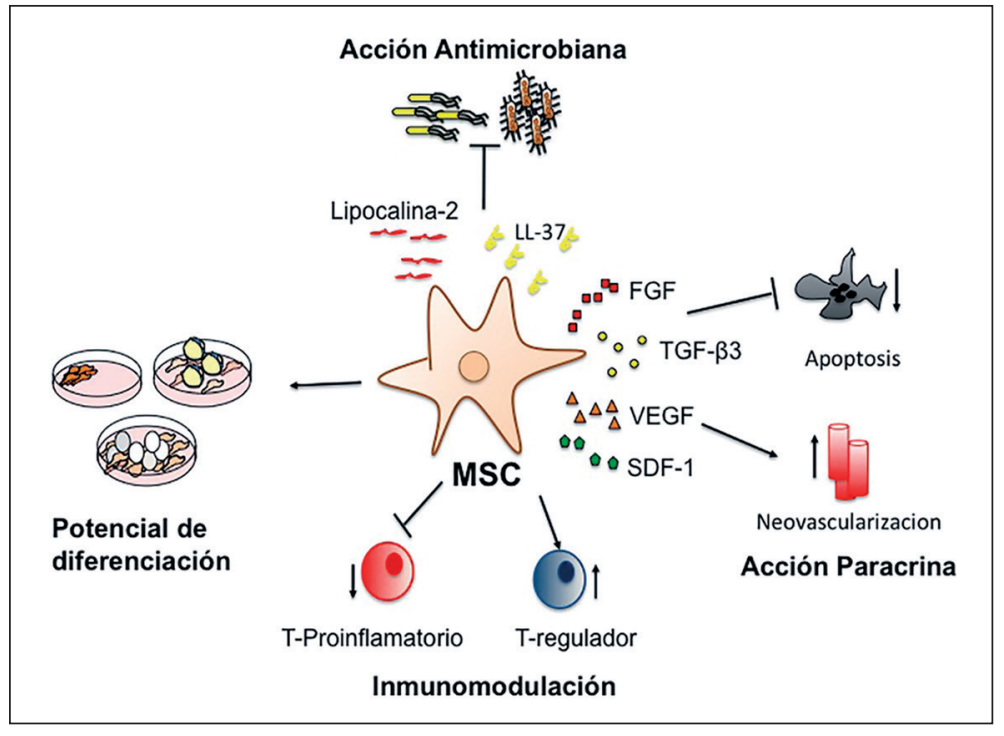

Figura 1. Resumen de los principales mecanismos ejercidos por las MSCs en sepsis, SDRA e IRA. 
Tabla 1. Resumen de los principales modelos preclínicos en sepsis

\begin{tabular}{|c|c|c|c|}
\hline Autor/Ref & $\begin{array}{l}\text { Fuente/ } \\
\text { dosis }\end{array}$ & Efectos biológicos & Efectos clínicos \\
\hline $\begin{array}{l}\text { Xu et al, } \\
2007^{24}\end{array}$ & $\begin{array}{l}\mathrm{MO} \\
5 \times 10^{5}\end{array}$ & $\begin{array}{l}-\downarrow \text { citoquinas pro-inflamatorias } \\
\text { - } \downarrow \text { infiltración neutrofílica en el pulmón } \downarrow \text { edema pulmonar }\end{array}$ & Prevención de IPA \\
\hline $\begin{array}{l}\text { Nemeth et al, } \\
2009^{25}\end{array}$ & $\begin{array}{l}\mathrm{MO} \\
1 \times 10^{6}\end{array}$ & $\begin{array}{l}\text { - } \boldsymbol{\Downarrow} \text { citoquinas pro-inflamatorias } \\
\text { - } \boldsymbol{\text { PGE} 2 ~} \uparrow \text { fenotipo de tolerancia inmune }\end{array}$ & $\begin{array}{l}\text { 个 sobrevida } \\
\downarrow \text { IRA }\end{array}$ \\
\hline $\begin{array}{l}\text { Mei et al, } \\
2010^{26}\end{array}$ & $\begin{array}{c}\mathrm{MO} \\
2,5 \times 10^{5}\end{array}$ & 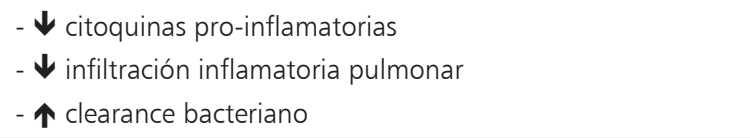 & $\begin{array}{l}\text { ヤ sobrevida } \\
\downarrow \text { disfunción orgánica }\end{array}$ \\
\hline $\begin{array}{l}\text { Krasnodembskaya } \\
\text { et al, } 2012^{27}\end{array}$ & $\begin{array}{l}\mathrm{MO} \\
1 \times 10^{6}\end{array}$ & 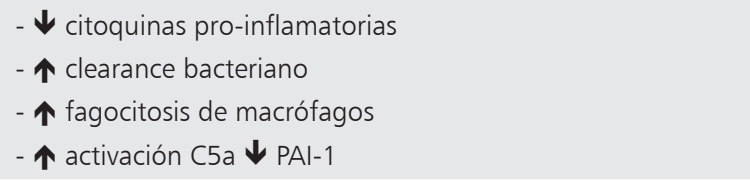 & ^ sobrevida \\
\hline $\begin{array}{l}\text { Hall et al, } \\
2013^{28}\end{array}$ & $\begin{array}{c}\mathrm{MO} \\
5 \times 10^{5}\end{array}$ & $\begin{array}{l}\text { - } \text { fagocitosis } \\
\text { - } \uparrow \text { clearance bacteriano }\end{array}$ & $\begin{array}{l}\boldsymbol{\uparrow} \text { sobrevida } \\
\downarrow \text { disfunción orgánica }\end{array}$ \\
\hline $\begin{array}{l}\text { Luo et al, } \\
2014^{29}\end{array}$ & $\begin{array}{c}\mathrm{MO} \\
1 \times 10^{6}\end{array}$ & $\begin{array}{l}\text { - } \uparrow \text { clearance bacteriano } \\
\text { - } \downarrow \text { citoquinas pro-inflamatorias e } \uparrow \text { IL-10 }\end{array}$ & $\begin{array}{l}\uparrow \text { sobrevida } \\
\downarrow \text { IRA }\end{array}$ \\
\hline
\end{tabular}

MO: médula ósea; IPA: injuria pulmonar aguda; IRA: injuria renal aguda; CD: células dendríticas; $\uparrow$ : aumento; $\boldsymbol{\Downarrow}$ : disminución.

el aumento de esta citoquina, que promueve la inmunotolerancia inhibiendo respuestas Th1 y Th17, depende de un efecto paracrino. Las MSC, mediante la liberación de PGE2, reprograman la acción de los macrófagos inflamatorios del huésped, cambiando su fenotipo e induciendo la liberación de IL-10.

La atenuación de la respuesta inmune podría tener un efecto deletéreo en el contexto de una infección grave, sin embargo la administración de MSC aumenta el clearance bacteriano, reflejándose en la disminución de CFU bacterianas en el torrente sanguíneo, bazo y pulmón. Dos péptidos con propiedades antimicrobianas secretados por las MSC han sido identificados, lipocalina-2 y LL-37 $7^{30,31}$.

Adicionalmente, el efecto antimicrobiano estaría en relación con mecanismos anti-apoptóticos y pro-fagocíticos que las MSC inducen en neutrófilos, monocitos y macrófagos. El factor paracrino $\mathrm{FGF}^{32}$ ha sido identificado en la inhibición de la apoptosis de células del sistema inmune innato.

Los efectos de las MSC han conducido a una disminución significativa de la mortalidad y falla orgánica en animales. Han sido documentados aumentos de la función cardiaca y disminución de los marcadores plasmáticos de disfunción renal y hepática. Paralelamente, ha sido reportada atenuación de la injuria pulmonar aguda, evidenciándose una disminución de la infiltración neutrofílica alveolar y del edema pulmonar ${ }^{24-29}$.

\section{Síndrome de distrés respiratorio agudo}

Los modelos utilizados son básicamente de dos tipos. En animales, frecuentemente ratones, se induce una injuria pulmonar mediada por ventilación mecánica (VILI) o por la aspiración orotraqueal $(\mathrm{AO})$ de bleomicina, LPS u otra endotoxina. Otros han utilizado un modelo de pulmón humano perfundido ex-vivo con rechazo inmunológico o en el cual se ha inducido una injuria pulmonar mediante Escherichia coli o una endotoxina. Las MSC se infunden por vía IV o AO y el timing de administración es variable. Un resumen de los efectos identificados se encuentra en la Tabla $2^{31,33-39}$.

La infusión de MSC, ya sea por vía local o sistémica, gatilla efectos inmunomodulatorios, la disminución del edema pulmonar y la reparación de la barrera alvéolo-endotelial.

$\mathrm{La}$ atenuación de las citoquinas pro-inflamatorias a nivel sistémico y pulmonar es una 
Tabla 2. Resumen de los principales estudios preclínicos en el SDRA

\begin{tabular}{|c|c|c|c|}
\hline Autor/Ref & $\begin{array}{l}\text { Fuente/ } \\
\text { dosis/vía adm }\end{array}$ & Efectos biológicos & Efectos clínicos \\
\hline $\begin{array}{l}\text { Rojas et al, } \\
2005^{33}\end{array}$ & $\begin{array}{l}\mathrm{MO} \\
5 \times 10^{6} \mathrm{IV}\end{array}$ & $\begin{array}{l}\text { - } \Downarrow \text { citoquinas pro-inflamatorias en pulmón } \\
\text { - } \downarrow \text { disminución daño histológico } \downarrow \text { fibrosis }\end{array}$ & $\boldsymbol{\Downarrow}$ mortalidad \\
\hline $\begin{array}{l}\text { Ortiz et al, } \\
2007^{34}\end{array}$ & $\begin{array}{l}\mathrm{MO} \\
5 \times 10^{5} \mathrm{IV}\end{array}$ & - MSC expresa IL-1 ra bloqueando IL-1, TNF- $\alpha$ & \\
\hline $\begin{array}{l}\text { Danchuk et al, } \\
2011^{35}\end{array}$ & $\begin{array}{c}\mathrm{MO} \\
2,5 \times 10^{5} \mathrm{AO}\end{array}$ & $\begin{array}{l}\text { - } \downarrow \text { citoquinas pro-inflamatorias + neutrófilos en LBA } \\
\text { - TSG-6: efectos anti-inflamatorios en pulmón }\end{array}$ & $\downarrow$ EPA \\
\hline $\begin{array}{l}\text { Gupta et al, } \\
2012^{31}\end{array}$ & $\begin{array}{l}\mathrm{MO} \\
5 \times 10^{5} \mathrm{AO}\end{array}$ & $\begin{array}{l}\boldsymbol{\Downarrow} \text { respuesta inflamatoria e } \boldsymbol{\uparrow} \text { clearance bacteriano alveolar } \\
\text { mediado por lipocalina } 2\end{array}$ & 个 sobrevida \\
\hline $\begin{array}{l}\text { Curley et al, } \\
2012^{36}\end{array}$ & $\begin{array}{l}\mathrm{MO} \\
2 \times 10^{6} \mathrm{IV}\end{array}$ & $\begin{array}{l}-\boldsymbol{\Downarrow} \text { daño histológico, } \boldsymbol{\Downarrow} \text { TNF } \alpha+\boldsymbol{\uparrow} \mathrm{IL}-10 \\
\text { - KGF: induce reparación epitelio alveolar }\end{array}$ & $\begin{array}{l}\downarrow \text { EPA } \\
\boldsymbol{\uparrow} \text { compliance }\end{array}$ \\
\hline $\begin{array}{l}\text { Lee et al, } \\
2013^{37}\end{array}$ & $\begin{array}{l}\mathrm{MO} \\
5-10 \times 10^{6}\end{array}$ & $\begin{array}{l}\text { - } \uparrow \text { clearance bacteriano } \uparrow \text { clearance alveolar } \downarrow \text { respuesta } \\
\text { inflamatoria }\end{array}$ & \\
\hline $\begin{array}{l}\text { McAuley et al, } \\
2014^{38}\end{array}$ & $\begin{array}{c}\mathrm{MO} \\
5 \times 10^{6}\end{array}$ & $\begin{array}{l}\text { - } \text { 个 clearance alveolar } \\
\text { - Reparación epitelio alveolar mediada por KGF }\end{array}$ & \\
\hline $\begin{array}{l}\text { Islam et al, } \\
2012^{39}\end{array}$ & $\begin{array}{l}\mathrm{MO} \\
2,5 \times 10^{5}\end{array}$ & $\begin{array}{l}\text { - Comunicación MSC-epitelio alveolar x nanotubos, transferencia } \\
\text { mitocondrial y } \uparrow \text { regeneración tisular }\end{array}$ & \\
\hline
\end{tabular}

IL1 ra: antagonista del receptor de IL1; LBA: lavado bronquioalveolar; TSG-6: TNFa-induced protein 6; EPA; edema pulmonar agudo; VILI: daño pulmonar inducido por ventilación mecánica; KGF: keratinocyte grow factor; PHPEV: pulmón humano perfundido ex-vivo; Rl: rechazo inmunológico.

constante y la inmunidad innata se ve favorecida incrementándose la actividad fagocitaria de monocitos y macrófagos, con el consiguiente efecto antimicrobiano descrito en sepsis. Una diversidad de factores paracrinos han sido identificados en la acción de las MSC en el SDRA. Ortiz et al. ${ }^{34}$ han demostrado que las MSC secretan un antagonista del receptor de IL-1 (IL-1ra) reprimiendo la producción de TNF- $\alpha$ y, por ende, la cascada inflamatoria. Danchuk et al. describieron el rol del factor soluble TSG-6, una proteína anti-inflamatoria, que media gran parte de los efectos inmunomoduladores de las MSC y cuya inhibición mediante un anticuerpo o "knockdown" anula sus efectos ${ }^{35}$.

El aumento del clearance alveolar permite reducir el grado de edema pulmonar. Lee et $\mathrm{al}^{37}$ han observado que lo anterior estaría mediado, en parte, por FGF-7.

Por último, Curley et al., y más recientemente Lee y McAuley et al., han observado que el uso de MSC permite una restauración del epitelio alveolar mediado por un factor paracrino denominado

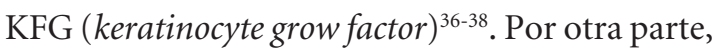
han comenzado a ser identificados mecanismos mediados por microvesículas. Islam et $\mathrm{al}^{39}$ han observado que las MSC son capaces de entrar en contacto con el epitelio alveolar y mediante la construcción de nanotubos transfieren material mitocondrial mediante microvesículas lo cual modifica el metabolismo de las células epiteliales y contribuye a la reparación epitelial.

El efecto clínico derivado de estas acciones es la disminución del daño histológico, incluyendo el grado de fibrosis, la disminución del edema pulmonar y el aumento de la sobrevida en modelos murinos.

\section{Injuria renal aguda}

El daño inducido por gentamicina, cisplatino e isquemia-reperfusión son los modelos más utilizados. La vía IV es la más frecuente, aunque algunos estudios han utilizado la vía intraperitoneal. El timing en la administración de las MSC es variable entre los estudios (previo a la injuria y 2 a 24 h post inducción de la injuria renal $)^{40-44}$. 
Los efectos de las MSC muestran un aumento en la tasa de proliferación de las células del epitelio tubular y una disminución en la apoptosis de éstas ${ }^{40}$. Chen et al. han observado una reducción del estrés oxidativo en el modelo de isquemia/ reperfusión ${ }^{41}$. El balance positivo proliferación/ apoptosis ha sido demostrado también in vitro, con la exposición de células tubulares al sobrenadante de las MSC. Lo anterior, así como en la sepsis y en el SDRA, subraya el rol de los efectos extracelulares mediados por las MSC. Particularmente, en los modelos de IRA, han sido identificadas dos moléculas con efecto paracrino: 1) Lipocalina-2, la cual muestra efectos estimuladores sobre la proliferación, inhibitorios sobre la apoptosis e induce un aumento en la expresión de factores de crecimiento y anti-oxidantes ${ }^{42}$ y 2) IGF-1, la que muestra también un efecto estimulatorio sobre la proliferación del epitelio tubular proximal ${ }^{43}$.

En comparación a los controles, la infusión de MSC disminuye significativamente los marcadores serológicos (creatinina y ácido úrico) de IRA, así como el daño histológico. Por el contrario, la infusión de MSC previo a la inducción de la injuria renal no ha demostrado un beneficio en la prevención de ésta ${ }^{44}$.

\section{Estudios clínicos con MSC en sepsis, SDRA e IRA (Tabla 3)}

Sepsis

Un ensayo clínico de fase I/II (NCT01849237) en pacientes con neutropenia $\left(<1 \times 10^{3}\right.$ cél $\left./ \mathrm{mm}\right)$ y shock séptico está en curso. La etiología de la neutropenia no ha sido especificada. Participan pacientes entre 17 y 75 años y se excluyen pacientes con patología oncohematológica y embarazadas. Se enrolarán 30 pacientes. Ni el origen ni la dosis de las MSC han sido precisados (1-2 millones $/ \mathrm{kg} /$ día). Las células se administrarán vía IV dentro de las primeras $10 \mathrm{~h}$ del diagnóstico del shock séptico. El outcome primario es la mortalidad a 28 días y como outcomes secundarios se encuentran: la reversibilidad del shock, la incidencia de disfunción orgánica y el impacto sobre parámetros inflamatorios (IL-6, IL-1, PCR, procalcitonina, etc.). El estudio no cuenta aún con resultados.

Un segundo ensayo de fase I (NCT02328612) se ha propuesto analizar el impacto de las MSC sobre la respuesta inflamatoria en hombres sanos que reciben una inyección intravenosa de LPS. El estudio es además un intento por determinar una dosis ideal basada en resultados. El ensayo

Tabla 3. Estudios clínicos con MSC en sepsis, SDRA e IRA

\begin{tabular}{|c|c|c|c|c|}
\hline & Fase & Objetivo & Pacientes & Estado/país \\
\hline \multicolumn{5}{|l|}{ Sepsis } \\
\hline NCT01849237 () & $|/| \mid$ & $\begin{array}{l}\text { Seguridad y eficacia de MSC alogénicas en } \\
\text { shock séptico y neutropenia }\end{array}$ & 30 & $\begin{array}{l}\text { En fase de reclutamiento/ } \\
\text { Rusia }\end{array}$ \\
\hline NCT02328612() & 1 & $\begin{array}{l}\text { Efectos de MSC alogénicas de origen adiposo } \\
\text { en voluntarios que reciben infusión IV de LPS }\end{array}$ & 32 & $\begin{array}{l}\text { En fase de reclutamiento/ } \\
\text { Holanda }\end{array}$ \\
\hline \multicolumn{5}{|l|}{ SDRA } \\
\hline NCT02097641 () & $|/| \mid$ & $\begin{array}{l}\text { Seguridad y eficacia de MSC alogénicas en } \\
\text { SDRA }\end{array}$ & 60 & $\begin{array}{l}\text { En fase de reclutamiento/ } \\
\text { USA }\end{array}$ \\
\hline NCT01902082 () & 1 & $\begin{array}{l}\text { Seguridad de MSC alogénicas de origen adipo- } \\
\text { so en SDRA }\end{array}$ & 20 & $\begin{array}{l}\text { En fase de reclutamiento/ } \\
\text { China }\end{array}$ \\
\hline \multicolumn{5}{|l|}{ IRA } \\
\hline NCT00733876 () & 1 & $\begin{array}{l}\text { Seguridad de MSC alogénicas en riesgo de IRA } \\
\text { post cardiocirugía }\end{array}$ & 15 & Terminado/USA \\
\hline NCT01602328() & ॥ & $\begin{array}{l}\text { Eficacia de MSC alogénicas en pacientes que } \\
\text { desarrollan IRA en las primeras } 48 \mathrm{~h} \text { de una } \\
\text { cirugía cardiaca }\end{array}$ & 156 & $\begin{array}{l}\text { En espera de resultados/ } \\
\text { USA }\end{array}$ \\
\hline
\end{tabular}


está reclutando individuos entre 18 y 35 años divididos en 4 grupos: placebo, grupos con $2,5 \mathrm{x}$ $10^{5}$ cél $/ \mathrm{kg}, 1 \times 10^{6}$ cél $/ \mathrm{kg}$ y 4 x $10^{6}$ cél $/ \mathrm{kg}$. Las MSC son de origen adiposo.

\section{Síndrome de distrés respiratorio agudo}

Liu et al. ${ }^{45}$ han publicado el diseño del primer ensayo clínico con MSC de médula ósea en el SDRA, el estudio START ("Stem Cells in ARDS treatment”) (NCT01775774 y NCT02097641). Se incluirán pacientes que en las primeras $96 \mathrm{~h}$ tengan PAFI $<200$ con PEEP $\geq 8$, cumpliendo los criterios de Berlín ${ }^{1}$ con un período predefinido de estabilidad clínica, oximétrica y hemodinámica de al menos $2 \mathrm{~h}$. La administración de las MSC ocurrirá antes de 120 h. En la fase I se realizará un análisis de dosis/tolerancia. Habrá 3 sujetos por cohorte, recibiendo $1 \times 10^{6}, 5 \times 10^{6}$ y $10 \times 10^{6}$ cél $/ \mathrm{kg}$ peso. La fase II utilizará las dosis máximas tolerables en la fase I con un diseño aleatorio, doble ciego. Se enrolarán 60 pacientes. El objetivo primario, tanto para fase I como II, será la seguridad y tolerancia de MSC alogénicas. Los objetivos secundarios serán los potenciales indicadores de eficacia del tratamiento, que podrán ser de 3 categorías: respiratorios, sistémicos y biológicos. Se estimará el score de injuria pulmonar (LIS) o score de Murray al día 3, la PAFI y el índice de oxigenación. Los pacientes deberán estar en decúbito supino y se manejarán con protocolos de ventilación protectora usando tablas de FiO2/PEEP, con estrategia de volemización conservadora.

\section{Injuria renal aguda}

Un ensayo clínico de fase I (NCT00733876) ${ }^{46}$ ha comprobado la seguridad en la administración alogénica de MSC en el postoperatorio de pacientes sometidos a una cirugía cardiaca con circulación extracorpórea con alto riesgo de desarrollar IRA. A los 16 meses ningún efecto adverso fue reportado y los datos preliminares muestran que la función renal es normal y que ninguno de los pacientes ha requerido diálisis. No obstante, el reporte del seguimiento a largo plazo (3 años) está pendiente. Otro ensayo de fase II (NCT01602328), que representa la continuación del estudio anterior, está en curso con 156 pacientes inscritos.

\section{Desafíos en el desarrollo de las MSC como herramienta terapéutica}

Actualmente la seguridad en la administración de MSC, sobre todo a corto plazo, no está en duda. Los estudios de fase I, en distintas patologías, no evidencian reacciones adversas, riesgos de inmunosupresión, embolia pulmonar o aumento de infecciones luego de una infusión aislada.

Las interrogantes se centran hoy en día en la dosis, periodicidad y seguridad del tratamiento con MSC a largo plazo. En este contexto, el destino de las células infundidas aún posee interrogantes. Las MSC poseen un tropismo para dirigirse a los sitios de inflamación y, en ausencia de ésta, se depositan mayormente en el pulmón, hígado y riñón ${ }^{47}$. Existe un porcentaje ínfimo que podría permanecer en un nicho específico por un tiempo prolongado. En modelos murinos, 50\% de los glomérulos de ratas que han sido tratadas con MSC evidenciaron un depósito adipocitario con signos de fibrosis ${ }^{48}$. Lo anterior indicaría una respuesta patológica a largo plazo o una diferenciación adipocitaria de MSC que se han injertado finalmente en el riñón.

Una manera de evitar este efecto indeseable es beneficiarse de los efectos terapéuticos de las MSC prescindiendo de ellas, lo que se ha denominado "cell-free therapy". Los factores paracrinos, como TSG-6, FGF-7, KGF, PGE-2 y otros podrían ser usados como terapia de manera independiente a las MSC. Así también, el campo relacionado a la producción de microvesículas y la transferencia de mitocondrias con material genético (ARN) ha abierto un nuevo campo de desarrollo.

Otras variables relacionadas a la producción, el costo, el marco sanitario y legislativo están fuera del alcance de esta revisión, pero son aspectos que hoy están en desarrollo.

\section{Conclusiones}

Durante los últimos 50 años, la investigación en el campo de la terapia celular, particularmente con MSC, ha proliferado de forma exponencial prometiendo revolucionar las estrategias terapéuticas que hoy conocemos.

Hasta el momento su potencial inmunomodulador y regenerativo ha sido objetivado mediante experimentación in vitro e in vivo en animales. 
En el campo de la medicina intensiva, además de la modulación del SIRS, se ha identificado un efecto paracrino antimicrobiano que hace atractiva la infusión de MSC como sinergia a la terapia antibiótica.

El mayor desafío es demostrar ahora el beneficio de la terapia celular en modelos clínicos. Por primera vez el conocimiento acumulado en ciencias básicas está siendo transferido a ensayos en humanos en sepsis, SDRA e IRA. De comprobarse su beneficio, las MSC podrían representar una alternativa terapéutica real en el paciente crítico con una sepsis o un SDRA refractarios a las medidas convencionales, así como para otros pacientes con enfermedades inflamatorias o auto-inmunes resistentes a la terapia inmunosupresora convencional.

\section{Referencias}

1. ARDS Definition Task Force, Ranieri VM, Rubenfeld GD, Thompson BT, Ferguson ND, Caldwell E, Fan E, et al. Acute respiratory distress syndrome: the Berlin Definition. JAMA 2012; 307 (23): 2526-33.

2. Kaukonen KM, Bailey M, Suzuki S, Pilcher D, Bellomo R. Mortality related to severe sepsis and septic shock among critically ill patients in Australia and New Zealand, 2000-2012. JAMA 2014; 311 (13): 1308-16.

3. Friedenstein AJ, Petrakova KV, Kurolesova AI, Frolova GP. Heterotopic of bone marrow. Analysis of precursor cells for osteogenic and hematopoietic tissues. Transplantation 1968; 6 (2): 230-47.

4. Friedenstein AJ, Chailakhyan RK, Latsinik NV, Panasyuk AF, Keiliss-Borok IV. Stromal cells responsible for transferring the microenvironment of the hemopoietic tissues. Cloning in vitro and retransplantation in vivo. Transplantation 1974; 17 (4): 331-40.

5. Owen M, Friedenstein AJ. Stromal stem cells: marrow-derived osteogenic precursors. Ciba Found Symp 1988; 136: 42-60.

6. Caplan AI, Bruder SP. Mesenchymal stem cells: building blocks for molecular medicine in the 21st century. Trends Mol Med 2001; 7 (6): 259-64.

7. Hermann A, List C, Habisch HJ, Vukicevic V, Ehrhart-Bornstein $\mathrm{M}$, Brenner R, et al. Age-dependent neuroectodermal differentiation capacity of human mesenchymal stromal cells: limitations for autologous cell replacement strategies. Cytotherapy 2010; 12 (1): 17-30.

8. Cho KA, Ju SY, Cho SJ, Jung YJ, Woo SY, Seoh JY, et al. Mesenchymal stem cells showed the highest potential for the regeneration of injured liver tissue compared with other subpopulations of the bone marrow. Cell Biol Int 2009; 33 (7): 772-7.

9. Dominici M, Le Blanc K, Mueller I, Slaper-Cortenbach I, Marini F, Krause D, et al. Minimal criteria for defining multipotent mesenchymal stromal cells. The International Society for Cellular Therapy position statement. Cytotherapy 2006; 8 (4): 315-7.

10. Pittenger MF, Mackay AM, Beck SC, Jaiswal RK, Douglas R, Mosca JD, et al. Multilineage potential of adult human mesenchymal stem cells. Science 1999; 284 (5411): 143-7.

11. Mosna F, Sensebé L, Krampera M. Human bone marrow and adipose tissue mesenchymal stem cells: a user's guide. Stem Cells Dev 2010; 19 (10): 1449-70.

12. In 't Anker PS, Scherjon SA, Kleijburg-van der Keur C, de Groot-Swings GM, Claas FH, Fibbe WE, et al. Isolation of mesenchymal stem cells of fetal or maternal origin from human placenta. Stem cells 2004; 22 (7): 1338-45.

13. Mitrano TI, Grob MS, Carrion F, Nova-Lamperti E, Luz PA, Fierro FS, et al. Culture and characterization of mesenchymal stem cells from human gingival tissue. J Periodontol 2010; 81 (6): 917-25.

14. Chan RW, Schwab KE, Gargett CE. Clonogenicity of human endometrial epithelial and stromal cells. Biol Reprod 2004; 8 (6): 1738-50.

15. Prockop DJ, Gregory CA, Spees JL. One strategy for cell and gene therapy: harnessing the power of adult stem cells to repair tissues. Proc Natl Acad Sci USA 2003; 100 (S1): 11917-23.

16. Franquesa M, Hoogduijn MJ, Reinders ME, Eggenhofer E, Engela AU, Mensah FK, et al. Mesenchymal Stem Cells in Solid Organ Transplantation (MiSOT) Fourth Meeting: lessons learned from first clinical trials. Transplantation 2013; 96 (3): 234-8.

17. Le Blanc K, Ringden O. Immunomodulation by mesenchymal stem cells and clinical experience. J Intern Med 2007; 262 (5): 509-25.

18. Yagi H, Soto-Gutiérrez A, Parekkadan B, Kitagawa Y, Tompkins RG, Kobayashi N, et al. Mesenchymal stem cells: Mechanisms of immunomodulation and homing. Cell Transplant 2010; 19 (6): 667-79.

19. Luz-Crawford P, Kurte M, Bravo-Alegría J, Contreras R, Nova-Lamperti E, Tejedor G, et al. Mesenchymal stem cells generate a CD4+CD25+Foxp3+ regulatory $\mathrm{T}$ cell population during the differentiation process of Th1 and Th17 cells. Stem Cell Res Ther 2013; 4 (3): 65.

20. Meirelles Lda S, Fontes AM, Covas DT, Caplan AI. Mechanisms involved in the therapeutic properties of 
mesenchymal stem cells. Cytokine Growth Factor Rev 2009; 20 (5-6): 419-27.

21. Wagner W, Horn P, Castoldi M, Diehlmann A, Bork S, Saffrich R, et al. Replicative Senescence of Mesenchymal Stem Cells: A Continuous and Organized Process. PLoS One 2008; 3 (5): e2213.

22. Polzer H, Volkmer E, Saller MM, Prall WC, Haasters F, Drosse I, et al. Long-term detection of fluorescently labeled human mesenchymal stem cell in vitro and in vivo by semi-automated microscopy. Tissue Eng Part C Methods 2012; 18 (2): 156-65.

23. Lee JW, Fang X, Krasnodembskaya A, Howard JP, Mathay MA. Concise review: Mesenchymal stem cells for acute lung injury: role of paracrine soluble factors. Stem Cells 2011; 29 (6): 913-9.

24. Xu J, Woods CR, Mora AL, Joodi R, Brigham KL, Iyer $\mathrm{S}$, Rojas M. Prevention of endotoxin-induced systemic response by bone marrow-derived mesenchymal stem cells in mice. Am J Physiol Lung Cell Mol Physiol 2007; 293 (1): L131-41.

25. Németh K, Leelahavanichkul A, Yuen PS, Mayer B, Parmelee A, Doi K, et al. Bone marrow stromal cells attenuate sepsis via prostaglandin E(2)-dependent reprogramming of host macrophages to increase their interleukin-10 production. Nat Med 2009; 15 (1): 42-9.

26. Mei SH, Haitsma JJ, Dos Santos CC, Deng Y, Lai PF, Slutsky AS, et al. Mesenchymal stem cells reduce inflammation while enhancing bacterial clearance and improving survival in sepsis. Am J Respir Crit Care Med 2010; 182 (8): 1047-57.

27. Krasnodembskaya A, Samarani G, Song Y, Zhuo H, Su $\mathrm{X}$, Lee JW, et al. Human mesenchymal stem cells reduce mortality and bacteremia in gram-negative sepsis in mice in part by enhancing the phagocytic activity of blood monocytes. Am J Physiol Lung Cell Mol Physiol 2012; 302 (10): L1003-13.

28. Hall SR, Tsoyi K, Ith B, Padera RF Jr, Lederer JA, Wang $\mathrm{Z}$, et al. Mesenchymal stromal cells improve survival during sepsis in the absence of heme oxygenase-1: the importance of neutrophils. Stem Cells 2013; 31 (2): 397407.

29. Luo CJ, Zhang FJ, Zhang L, Geng YQ, Li QG, Hong Q, et al. Mesenchymal stem cells ameliorate sepsis-associated acute kidney injury in mice. Shock 2014; 41 (2): 123-9.

30. Krasnodembskaya A, Song Y, Fang X, Gupta N, Serikov $\mathrm{V}$, Lee JW, et al. Antibacterial effect of human mesenchymal stem cells is mediated in part from secretion of the antimicrobial peptide LL-37. Stem Cells 2010; 28 (12): 2229-38.

31. Gupta N, Krasnodembskaya A, Kapetanaki M, Mouded
M, Tan X, Serikov V, et al. Mesenchymal stem cells enhance survival and bacterial clearance in murine Escherichia coli pneumonia. Thorax 2012; 67 (6): 533-39.

32. Walter J, Ware LB, Matthay MA. Mesenchymal stem cells: mechanisms of potential therapeutic benefit in ARDS and sepsis. Lancet Respir Med 2014; 2 (12): 101626.

33. Rojas M, Xu J, Woods CR, Mora AL, Spears W, Roman $\mathrm{J}$, et al. Bone marrow-derived mesenchymal stem cells in repair of the injured lung. Am J Respir Cell Mol Biol 2005; 33 (2): 145-52.

34. Ortiz LA, Dutreil M, Fattman C, Pandey AC, Torres G, Go $\mathrm{K}$, et al. Interleukin 1 receptor antagonist mediates the antiinflammatory and antifibrotic effect of mesenchymal stem cells during lung injury. Proc Natl Acad Sci U S A 2007; 104 (26): 11002-7.

35. Danchuk S, Ylostalo JH, Hossain F, Sorge R, Ramsey A, Bonvillain RW, et al. Human multipotent stromal cells attenuate lipopolysaccharide-induced acute lung injury in mice via secretion of tumor necrosis factor- $\alpha$-induced protein 6. Stem Cell Res Ther 2011; 2 (3): 27.

36. Curley GF, Hayes M, Ansari B, Shaw G, Ryan A, Barry $F$, et al. Mesenchymal stem cells enhance recovery and repair following ventilator-induced lung injury in the rat. Thorax 2012; 67 (6): 496-501.

37. Lee JW, Krasnodembskaya A, McKenna DH, Song Y, Abbott J, Matthay MA. Therapeutic effects of human mesenchymal stem cells in ex vivo human lungs injured with live bacteria. Am J Respir Crit Care Med 2013;187 (7): 751-60.

38. McAuley DF, Curley GF, Hamid UI, Laffey JG, Abbott J, McKenna DH, et al. Clinical grade allogeneic human mesenchymal stem cells restore alveolar fluid clearance in human lungs rejected for transplantation. Am J Physiol Lung Cell Mol Physiol 2014; 306 (9): L809-15.

39. Islam MN, Das SR, Emin MT, Wei M, Sun L, Westphalen K, et al. Mitochondrial transfer from bone-marrow-derived stromal cells to pulmonary alveoli protects against acute lung injury. Nat Med 2012; 18 (5): 759-65.

40. Bi B, Schmitt R, Israilova M, Nishio H, Cantley LG. Stromal cells protect against acute tubular injury via an endocrine effect. J Am Soc Nephrol 2007; 18 (9): 248696.

41. Chen YT, Sun CK, Lin YC, Chang LT, Chen YL, Tsai $\mathrm{TH}$, et al. Adipose-derived mesenchymal stem cell protects kidneys against ischemia-reperfusion injury through suppressing oxidative stress and inflammatory reaction. J Transl Med 2011; 9: 51.

42. Halabian R, Roudkenar MH, Jahanian-Najafabadi A, Hosseini KM, Tehrani HA. Co-culture of bone marrow-derived mesenchymal stem cells overexpressing 
lipocalin 2 with HK-2 and HEK293 cells protects the kidney cells against cisplatin-induced injury. Cell Biol Int 2015; 39 (2): 152-63.

43. Imberti B, Morigi M, Tomasoni S, Rota C, Corna D, Longaretti $\mathrm{L}$, et al. Insulin-like growth factor-1 sustains stem cell mediated renal repair. J Am Soc Nephrol 2007; 18 (11): 2921-8.

44. Reis LA, Borges FT, Simões MJ, Borges AA, Sinigaglia-Coimbra R, Schor N. Bone marrow-derived mesenchymal stem cells repaired but did not prevent gentamicin-induced acute kidney injury through paracrine effects in rats. PLoS One 2012; 7 (9): e44092.

45. Liu KD, Wilson JG, Zhuo H, Caballero L, McMillan ML, Fang X, et al. Design and implementation of the START (STem cells for ARDS Treatment) trial, a phase $1 / 2$ trial of human mesenchymal stem/stromal cells for the treatment of moderate-severe acute respiratory distress syndrome. Ann Intensive Care 2014; 4: 22.

46. Tögel FE, Westenfelder C. Kidney protection and regeneration following acute injury: progress through stem cell therapy. Am J Kidney Dis 2012; 60 (6): 1012-22.

47. Gao J, Dennis JE, Muzic RF, Lundberg M, Caplan AI. The dynamic in vivo distribution of bone marrow-derived mesenchymal stem cells after infusion. Cells Tissues Organs 2001; 169 (1): 12-20.

48. Kunter U, Rong S, Boor P, Eitner F, Müller-Newen G, Djuric Z, et al. Mesenchymal stem cells prevent progressive experimental renal failure but maldifferentiate into glomerular adipocytes. J Am Soc Nephrol 2007; 18 (6): 1754-64. 